\title{
Business Strategies Based on Large Sets of Data and Interaction: Business Intelligence
}

\author{
Juan Luis Peñaloza Figueroa \\ Department of Statistics and Operations Research II \\ Complutense University of Madrid \\ Carmen Vargas Pérez \\ Department of Applied Economics IV \\ Complutense University of Madrid
}

\begin{abstract}
.
The dominant perspective in Business Intelligence $(\mathrm{BI})$ projects and applications has been the technological conception, usually focused on the technical-instrumental nature of computing. This conception has avoided the change in the paradigm from a business model based on the use of tangible resources in favour of one based on the exploitation of intangible resources (data, interaction, networks, etc.). This would explain why applied BI projects, remain anchored in the old organization and operational patterns of traditional businesses in most companies. The technological perception of BI gives continuity to the stovepipe activity of companies, both in their management and in their organizational structures, where the impact of interaction as a generator of business opportunities is very limited, and often non-existent; and the effect of large volumes of data as a value generator is reduced to an operational and technical problem. Hence, the importance of considering BI as a new business philosophy that entails new forms of business organization and a new way of management based on the interaction and analysis of large volumes of internally generated data. Our interest is not only to emphasize the nature of the new business philosophy in the application of $\mathrm{BI}$, but to carry out a discussion about the organizational and operational structure of businesses -according to a conception based on interaction and data as generators of business value-, and about actionable intelligence.
\end{abstract}

Keywords: business philosophy, paradigm, intelligence, stovepipe organization, business opportunities, business value. JEL classification: G14, J24, M20, M21, M54

\section{Introduction}

During the last decades it has become evident that the way the value of a business is measured has changed completely. Traditionally, this valuation has been associated with the tangible assets of the companies, although today this is not exactly like this. Increasingly, a company's value is measured on the basis of intangible assets whose objective values such as customer satisfaction, process quality, brand image, the company's intellectual capital, the interaction between their workers, the large volume of data they have, etc. are not easy to assess.

In this context, this study advances in the elucidation of whether the valid conception of Business Intelligence (BI) is a set of technological tools external to the dynamics of the company and that adapts to the circumstances that the company lives or, on the contrary a new model of configuration of the company based on organizational, managerial and actionable intelligence, in which technology plays the role of connector, support and motorway, through which information and transferred knowledge flows.

In addition, in a world where companies change rapidly and business processes become increasingly complex and difficult for executives to interpret, for getting a global understanding of the business environment in which they operate, we propose an organizational structure that responds to the new parameters of actionable intelligence, related to the generalized use 
of intangible resources, the configuration of the communication network as information channels, and the use of the company's collective intelligence.

This research was motivated by the search for answers to questions related to the change in the business paradigm in which BI systems play a decisive role in the organization, operation and evaluation of the company's activity. The rest of this document is organized as follows. Section 2 addresses the problem of a $\mathrm{BI}$ conception in an intangible resource environment. Section 3 analyzes the history and background of business logic in relation to the exploitation of intangible resources. Section 4 presents an approach to the nature of the new business philosophy in the Bl environment as a new basis for its organization and operation. In Section 5 we present and discuss the new organizational architecture that responds to the parameters of $\mathrm{Bl}$ and the exploitation of collective intelligence. In Section 6 we conduct a brief discussion on the future of $\mathrm{BI}$ in which we emphasize the new challenges faced by companies in the 21 st century, and propose some future lines of research. Finally, we present the conclusions.

\section{Problem Statement}

Today, both entrepreneurs and their executives have the task of overcoming new challenges. Therefore, they must carry out strategies in line with the changing circumstances that characterize their environment, their resources and capabilities, their internal and external expectations about the organization, and the logic underlying their behavior, usually conflicting with each other. However, the relevant question remains: whether the current business model can respond to the changes brought about by the knowledge and the digital economy.

In this context, the emergence of technological innovation, as a factor of change in the fundamentals of how to create value, has given rise to the predominance of a technological conception of $\mathrm{BI}$ projects and applications. This view, that is usually centered on the techno-instrumental nature of technology, has sidestepped the change from the business paradigm based on the use of tangible resources in favor of a business model based on the exploitation of intangible resources (data, interaction, networks, etc.). Additionally, it assumes that technology itself can determine economic and business performance in terms of growth or employment, under the argument that its use will shape the evolution of business architecture.

The effects of this way of understanding business become evident in the limitations in the depth of the companies' processes of change, which are still anchored in the old business organizational and operational ways. Companies continue to fill in their annual reports with information on how they use tangible capital and how they control their workers, but they do not reflect the use they make of their increasingly "knowledge-intensive" employees, that drive the creation of wealth in the current digital economy (Passlick, et. al., 2017; Von Bergen, et. al., 2015; Satiko, et. al., 2015; Khan, 2012).

Moreover, this technological perception of BI has given continuity to business activity by stovepipe segments, both in its management and in its organizational structure, in which the impact of interaction as a generator of business opportunities has been limited, and often non-existent. Similarly, the effect of using large volumes of data as a value generator has been reduced to an operational and technical problem.

These facts raise the need to decipher the nature of BI to make it possible to identify and make explicit the new business philosophy implicit in it, the new business architecture that it suggests and the new management methods which are focused on the interaction and the analytics of large volumes of internally generated data, in addition to the ability to align them with the company's business strategy, goals and targets.

\section{History and Background of Business Logic and Intangible Resources}

At the beginning of the 2008 crisis we were faced with a picture characterized by the absolute control of short-term strategies, the exclusive use of financial indicators as a criterion for measuring business success and the excessive weight of investors as the dominant group at the expense of customers, employees and society as a whole.

Added to this is the steady increase in the value of the intangible assets and resources in the last three decades. In fact, intangible assets have been behind some of the biggest initial public offerings (IPOs) and the exponential increase in the stock market prices of certain companies over the last few years. Let us think, for example, of Facebook, Uber, or Twitter. None of these companies have tangible assets to back them up beyond a few offices and their information systems. None of these assets reflect a sufficient justification for the value of their stock market prices, according to traditional measurement criteria. 
In this environment, the standard microeconomic theory still continues to describe firms as predefined sets of linear relationships, whose operation can be understood as the meticulous assembly of all the pieces of something more complex. According to this theory, the behavior of the productive system can be deduced from a simple aggregation of its tangible components (fixed and/or variable capital and number of hours worked or number of workers). So the system of production will be formally defined by a function showing the relationships between tangible resources, to obtain a product:

$$
Q=f(K, L)
$$

where "K" represents the fixed and/or variable capital and "L" the labour used according to previously defined technical coefficients.

This conception of the company has perpetuated the competencies associated with fixed and financial capital throughout the $20^{\text {th }}$ century and part of the $21^{\text {st }}$ century. In fact, it has limited the space of competitiveness, almost exclusively, to the impact of financial variables, thus neglecting the role of other less measurable variables such as intangible assets.

In addition, the new economy, built on the knowledge and digitization of business activities and relations, empowers companies to collect distinctive competencies in certain types of intangible assets, that are totally different to tangible capital or to financial capital, factors that had a key role in industrial capitalism. The intangible-assets-based company refers precisely to the growing volume of investment in intangible assets, -which are often not even included in the corporate balance sheet- such as quality, collective intelligence, brand, reputation, managerial skills, organizational skills, innovative and technological skills, human capital, knowledge of markets, customers and competitors, etc.

Formally speaking, the production model in this environment would be defined by a function whose arguments include the interactive relationships between the different intangible resources and their effect on production.

$$
Q=f(I, G C D, R, \ldots)
$$

where "I" measures the effects of interaction, "GCD" reflects the effect of the exploitation of large data sets, "R" registers the reputation achieved by the firm, etc.

This process of change in the relations of production has been made possible by the current digitization process of economies, characterized by the increasing empowerment of public opinion, customers, qualified employees, regulators, shareholders, suppliers, etc. A process of change that has substantially changed the way companies and entities are organized, moving from an asymmetric relationship favourable exclusively to the decisions of senior executives, to another in which relations of interaction and dialogue at the same level predominate (collective intelligence), both in their operations and in the decentralization of decision-making.

Intangible assets, while difficult to isolate and measure, create value and improve the competitive position of the company and its economic results. Intangible assets represent an increasing proportion of corporate value, as financial results and profitability increasingly respond to the interaction and management of ideas, information, knowledge and services, rather than to the control of tangible resources.

According to the latest Global 500 annual reports, the generation of value of the North American companies settled in the United States has been reversed from a ratio of 70\%-30\% between the value of tangible and intangible assets from 1929 to 1999 , to a ratio of $30 \%-70 \%$ in favor of business intangibles. For example, IBM's brand value represents $83 \%$ of the total value of the company, Coca-Cola reaches $96 \%$ and Kellogg's 97\%; and in the internet and telephone companies that proportion exceeds 90\%. (Alloza, 2016; Brand Finance Global 500, 2016-17).

The catalyst for the development of this new business model -BI- has been the breakup of disruptive innovation -a term created by Christensen from the Harvard Business School-, which impacts business and/or productive activity, causing drastic changes in the organizational logic and the operating dynamics of companies, motivating in many cases a change in the line of business of the company. These changes allow us to understand the nature and features of nesting the new model of business-intelligent enterprise inside the industry and the knowledge economy. 


\section{Nature of the New Business Philosophy in the Business Intelligence Environment}

The company and the market, as the scenario where it operates freely, are facing today a series of challenges and pressures that are reshaping the very nature of the corporate objectives, the organizational functions and responsibilities, the role of physical and virtual markets, the way of doing business, etc. Changes in this environment have been generated by powerful latent forces of very different nature, causing changes in the characteristics of the labour market and the business paradigm, under the umbrella of a series of technological, economic and social vectors; challenges that companies in the 21 st century have to face and which are significantly different from the traditional problems encountered over the past century.

The implementation of intelligent business systems, in increasingly digitized economic environments, requires a model and a technology that facilitates permeability, intelligent interactivity, evaluation, diagnosis, and that determines the right level of intelligence ${ }^{1}$ for the company. The aim is to improve the decentralized decision-making system based on intangible resources and to gain competitive advantage through the intelligent management of knowledge.

$\mathrm{BI}$ is a new business organization system that makes use of analytical and visual technology to facilitate analytical, graphical or actionable intelligence. In other words, it is a conception that, in the first place, explains the characteristics of the new business model and, in addition, shows the advantages of using new technologies to deliver information and/or knowledge, to facilitate reporting and consultation, and to improve decision making (Azevedo \& Santos, 2009, Turban et. al., 2008, Clark et. al., 2007, Michalewicz et. al., 2007, Negash, 2004, Raisinghani, 2004, Moss \& Shaku, 2003, Kudyba \& Hoptroff, 2001 and Thierauf, 2001). In short, they are the two sides of the same coin, in the sense that technological innovation is inseparable from organizational innovation.

Generally, the definition of BI not only makes use of different terms, but also the content of the concept varies, depending on the "theoretical" emphasis or preferences of scholars or professionals in the business world. In essence, and despite the advances in business theory, Bl is still considered as an external analytical "tool" and an automatic support for decision making regarding business conditions, sales and customer demand, among many other conditions (Kahraman, et. al., 2011, Ghazanfari et. al., 2011, Berson \& Smith, 1997).

This vision emphasizes the technological characteristics that accompany BI projects, although with nuances. Nuances all of them aimed at broadening the range of implementation of the intelligent technological tools (Bose, 2009; Elbashir, 2008; Power, 2008; Ranjan, 2008; Watson \& Wiixom, 2007; Wu 2007; Ekeerson 2005; Maria, 2005).

In essence, the perception of $\mathrm{BI}$ as a set of external support tools is one of the key factors that gives continuity to the traditional organizational architecture of the company and perpetuates traditional business management ways, an issue that we will address in the following Section.

In this environment, the dominant practice has been the use of the term "adaptation" as a "mechanism" for adjusting the technological tools associated with BI to the traditional organizational forms of today's business activities. In this case, the evidence shows that less than $30 \%$ of the implemented BI projects have been able to meet the expected benefits of the companies, even though these projects have had almost two decades to be implemented (Von Bergen, et. al. 2015; Saran, 2012). Hence, the importance of overcoming this BI technological vision, which separates the business model and the technology as independent events, to associate it with the new business philosophy that entails new forms of organization of the company and the intelligent use of technology innovation, substantiated on the management and tracking of interaction, collective intelligence and the integration of the analysis of large volumes of data, internally and externally generated.

From our point of view, $\mathrm{BI}$ has evolved considerably since its origin and first scientific definition -as an external management tool-, that helps the company to manage and redefine business information (Ghoshal \& Kim, 1986). Today, BI makes it clear and shows the strong association between knowledge management and competitive intelligence (Azevedo, 2009;

\footnotetext{
${ }^{1}$ In this work we talk about intelligence in terms of information as opportunity or possibility, that is, knowledge structures that, being contextually relevant, allow an advantageous intervention in reality (to be succesful). Thus, it refers to the set of integrated capabilities as a unit: learning, feeling, incorporating, linking, experiencing and communicating.
} 
Zeller, 2008; Turban et. al., 2008; Clark et. al., 2007 and Liebowiz, 2006), in addition to intelligent exploration, integration, aggregation and multidimensional analysis of data from various sources. (Yeoh \& Koronios, 2010; Olszak \& Ziemba, 2007).

This finding confirms that this is a new business philosophy or a new business model, which involve an organizational architecture that differs substantially from the traditional ways of organization of companies organized in stovepipe departments. This new philosophy is accompanied by a system of business management functions, in which new technologies have the role of facilitators and connectors of the elements of the new organizational model of companies, in contrast to the traditional system based on authoritarianism, the absolute hierarchy of internal relations, and the passive role to human capital in the dynamics of the company.

\section{The New Organizational Architecture and Business Intelligence}

Business architecture constitutes the way to integrally describe the company, and it involves each and every element that shapes it. The key structure of this architecture is the organizational one, which has the role of organizing all the activities developed by the company, grouping them according to their long-term objectives, in order to respond to the new division of labour, the new immaterial production factors, the modern communication channels and the specification of decentralized responsibilities, in accordance with the long term goals and the strategies defined by the company.

However, traditional business logic has not really become aware of the change in the business paradigm and continues to rely, basically, on maintaining the usual forms of organization, due, in large part, to the difficulties interpreting the impact of the new challenges posed by paradigmatic change, especially when strategic issues are full of complexity and uncertainty. In addition, the inertia that leads executives to resort to proven "solutions", that help them minimize the uncertainty associated with change, must be taken into account; solutions that were successful in the past and were consistent with traditional organizational routines.

This strategy means giving continuity to an organizational architecture that reproduces the departmental structure of business activity, usually following a stovepipe model, as a key factor for carrying out the basic operations of the company. And this has its foundation, in the first place, in the principle of departmentalization which consists of grouping the tasks and functions in functional areas or departments with little permeability, in order to manage the different activities of the company, regardless of the relationships that underlie its operations; examples of this are finance and accounting, marketing and sales, human resources, production, and purchasing departments. And, secondly, in the steering unit principle that establishes the need for a single manager or a single boss (prioritizing the role of executives who occupy the highest positions) who is the only one in charge of defining the goals and strategies of the company, in addition to the control and supervision of the whole system and the achievement of the goals of the company (see figure 1).

\section{Figure 1. Traditional Organizational Diagram}

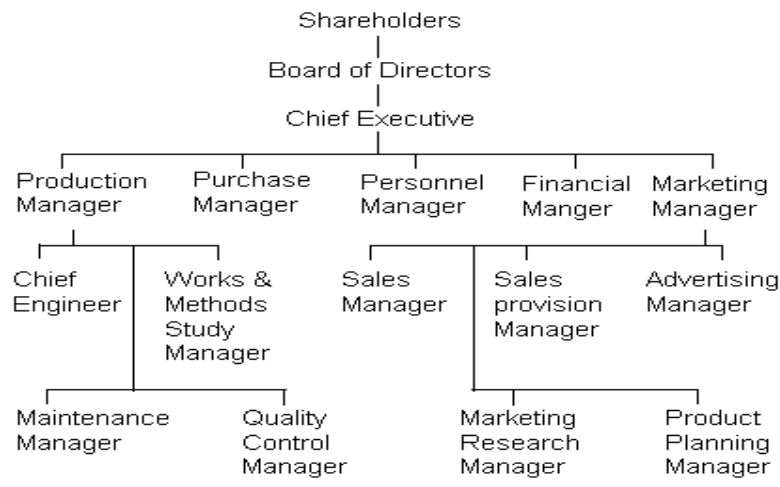

Source: Own elaboration 
In this scenario, the various efforts to adapt these old structures to the new knowledge-based economic environment and to the impact of technological innovation on non-tangible production factors seem to have failed to achieve their main goal: the development of competencies, skills and abilities sufficient to capture the intelligence and the experience of workers and to encourage a strategic business culture of continuous learning, creativity and willingness to change.

Moreover, most executives and scholars continue to insist on the viability of the bureaucratic and rigid structures that characterize traditional companies, believing that overlapping a technological communication structure that speeds up the operations and transactions of the company will be sufficient to align the long-term business strategies with the short-term actions and practices; a strategy that has become one of the limiting factors for the expected change.

The growing application of science and technology in business, through the process of technological innovation, has highlighted the configuration of productive activity around a balance defined by the acquisition of new competencies related to knowledge management, and new operational skills associated with the management of new technological innovations.

This process is twofold; first, the workers of the company acquire business knowledge for a permanent and continuous innovation in environments of risk and uncertainty and, secondly, manufactured goods and services are created with a high added value content.

Within this framework of change of the business paradigm in favour of a flexible business architecture, focused on the exploitation of intangible resources (interaction, large data sets, networks, talent, reputation, brand, etc.), companies should be able to evolve at the pace of change of their environment, not only in their organizational structure, but also in the management systems implemented (intelligent cooperation, interaction and complementarity among teams, decentralization of decisions, etc.).

This new economy built on knowledge and the digitization of business relationships empowers companies to acquire distinctive competencies in certain types of intangible assets that are totally different to tangible capital or financial capital. In this knowledge era, the survival of the company will be linked to its ability to capture people's intelligence and experience and, relying on new technologies and knowledge management systems, transform them into useful knowledge to encourage learning, creativity and innovation, in companies or organizations.

Thus, the 21 st century company is increasingly dependent on people's competencies, skills and abilities (talent) compared to the past. BI not only has the ability to capture, process and distribute information and codified knowledge, making use of technology, but it is also able to manage the business demand for greater tacit knowledge, which can only be located in the intelligence and experience of people, and transferred by direct contact.

Today's business organizational design, imposed by the interaction, the automation, the digitization and new analysis and the visualization technologies requires workers with creative abilities, tracking and mapping skills, and with operational aptitudes to use the new technologies in the exploitation and visualization of large datasets, as well as the graphic skills necessary for automatic presentation of results.

In this knowledge economy, organizational design should be flexible and reversible in order to make possible the total transformation of the company, to respond to changes in market conditions and to incorporate the impact of technological innovations. The structure consistent with these demands is based on the formation of highly interrelated and complementary work teams with different mechanisms of network communication (intranet), permeable to brainstorming, and encouraged to decentralized decision-making. This design includes management teams in communication, market and clients, talent and multipurpose staff, creativity and invention, technological innovation, production and logistics, etc., all closely related to the team of analysts, and intelligently managed (See figure 2). 


\section{Figure 2. New Organizational (Flexible and Multipurpose) Diagram}

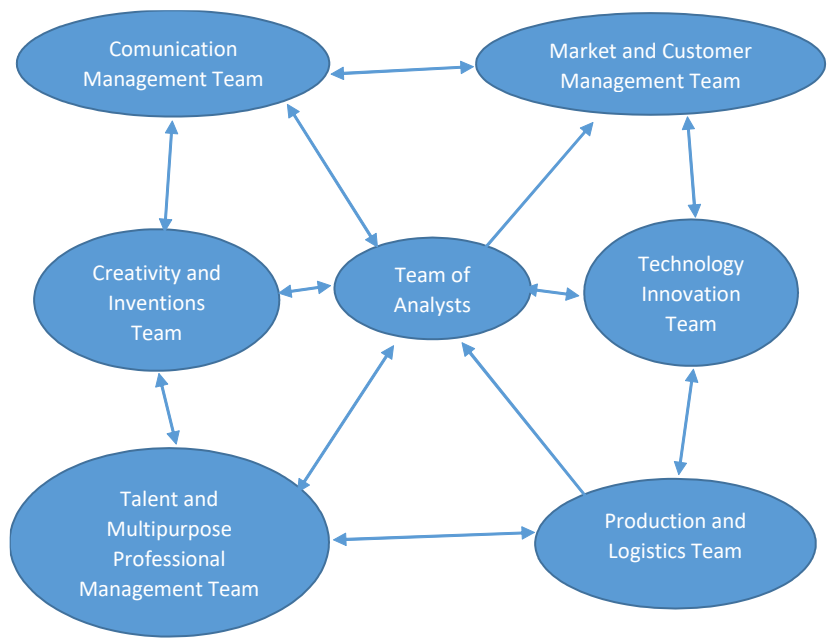

Source: Own elaboration

This organizational architecture allows to align processes, data, applications and technological infrastructure with the strategic objectives of the company or with the raison d'être of business organizations. And it meets the requirements of the $\mathrm{BI}$ model that acts as a system that integrates the strategic level with the business level of the process. This architecture records all the ways in which the different management teams relate to each other, and how they remain internally united, to generate value-generating projects, manage the asymmetry of customer relationships, and diagnose the financial situation of the company. It also documents the ways of communication of information between clients and suppliers, and inside the company itself.

Table 1 shows the different activities that define the management teams in a flexible and reversible organizational architecture. For example, the impact of technological change on the nature of work, on the usable know-how and on the configuration of labour has stimulated and accelerated the break with the old ways of administering human resources departments. In fact, it has modified the keys to the company's survival by linking them to its ability to capture multi-purpose intelligence and the experience of the new generation professionals ${ }^{1}$ by giving way to the formation of a Talent and multipurpose professional management team.

\section{Table 1. Analytics of Management Teams}

Talent and multipurpose

professional management team
Determines if the members of the teams are creative and innovative.

Estimates the likelihood that teams will implement less innovative solutions.

Establishes whether teams include professionals with high theoretical or statistical training and/ or mathematical skills.

\footnotetext{
1 In this work we understand that there is a clear difference between the concepts of "Administrator" and "Manager". The first refers to the continuity of a static stewardship of the company based on the absence of substantial changes in the dynamics of the operation of the company and the inefficient use of existing tangible resources, probably eliminating those that are "expendable". On the contrary, the second refers to a dynamic leadership of the company, whose starting point is setting medium and long term targets, and defining the operation of the company based on the efficienct use of tangible and intangible resources.
} 


\begin{tabular}{|c|c|}
\hline & $\begin{array}{l}\text { Determines whether teams have the necessary predictive and forecasting capabilities to } \\
\text { meet the company's strategic objectives. }\end{array}$ \\
\hline Communications management team & $\begin{array}{l}\text { Indicates the degree of communication reached: one or several sources of information, from } \\
\text { news or databases. } \\
\text { Presents the information classified by topics/types or areas of knowledge, updated and in } \\
\text { real time. } \\
\text { Geolocalizes the information or news, and communicates to the list of users of the } \\
\text { company's platform (workers, customers, suppliers, etc.). } \\
\text { Validates the information by examining the credibility of the source of the information. }\end{array}$ \\
\hline $\begin{array}{l}\text { Market and customer management } \\
\text { team }\end{array}$ & $\begin{array}{l}\text { Proposes and formulates marketing strategies targeted to specific groups of customers. } \\
\text { Carries out the tracking and mapping of the interaction with customers. } \\
\text { Proposes intelligent models for customer loyalty based on the client's experience with the } \\
\text { company. } \\
\text { Makes future projections of customers' value based on their life cycle and purchase. } \\
\text { Manages the shopping experience of digital natives (consumers of the future) and creates } \\
\text { portfolios of products and channels. }\end{array}$ \\
\hline Creativity and Inventions Team & $\begin{array}{l}\text { Designs projects to create new products and renews the range of products and services } \\
\text { Designs new strategies to generate a map of business opportunities. } \\
\text { Makes proposals for a transversal (or throughout the value chain) innovation and not just on } \\
\text { the product. } \\
\text { Extends the use of wireless technologies to speed up business transactions. }\end{array}$ \\
\hline Production and logistics team & $\begin{array}{l}\text { Maps the quality standards of the products and services manufactured. } \\
\text { Monitors the production coefficients used. } \\
\text { Manages and optimizes distribution network cycles. } \\
\text { Tracks the stocks and product repositories, in addition to the stocking system. }\end{array}$ \\
\hline Technology innovation team & $\begin{array}{l}\text { Carries out the monitoring of the technological needs of the different management teams. } \\
\text { Maps software update needs and the automation algorithms } \\
\text { Designs projects to build ad-hoc algorithms. }\end{array}$ \\
\hline Team of analysts & $\begin{array}{l}\text { Coordinates the formation and connection of management teams } \\
\text { Develops its activity in close relation with all the management teams. } \\
\text { Tracks the various management teams. } \\
\text { Compilates reports and carries out company diagnostics. }\end{array}$ \\
\hline
\end{tabular}

Source: Own elaboration

The impact of artificial intelligence has revolutionized communications to such an extent that today we speak of intelligent communication, which would be managed by the communications management team, and would have the purpose of capturing, analyzing and optimizing the communication of information, both inside and outside the company. The idea is to automatically find the information, treat it, analyze it and find a receiver (customer or professional) who is interested in that information.

Similarly, the market and customer management team is responsible for carrying out the tasks related to the marketing of products or services to specific groups, unlike traditional marketing interested in mass or generalist marketing. The real value comes from translating the data collected from the company's transactions into intelligence and then applying that intelligence to developing customer-based strategies (e.g. Banks, Supermarkets, Airlines, Hotels, Car Rental Companies or Taxi Fleets, etc.).

In relation to the creativity and inventions team, its activity makes sense when we refer to the abstract world of ideas (creativity) as well as to the successful implementation of these ideas into reality or to the process of materializing those ideas (inventions). In other words, creative intelligence is the input for inventions, and only through the application of intelligence creativity can be made tangible.

Likewise, the production and logistics team is responsible for tracking and mapping the process of manufacturing products or services, in addition to the efficient and intelligent use of resources in the production chain. Intelligence in logistics is a way to improve efficiency of the flow of products and inputs. When addressing the classification of the logistics service,the specific characteristics of the company must be taken into account. For example, IKEA divides its products by flow categories: high or low, HOME DEPOT designs different distribution channels for its products based on the circulation 
and the size of its products and AMAZON divides customers into different service groups (Highland 2014; Wilding \& Juriado 2004; Knemeyer, Corsi, et, al., 2003; Bolumole 2001; Rabinovich, Windle, et. al., 1999).

Similarly, the technological innovation team is responsible for coordinating the actions related to the support to the different activities of the teams, and for tracking the technological needs of the company.

Lastly, we have the team of analysts whose role in $\mathrm{BI}$ is to facilitate decentralized decision making in the company. To do so, it makes use of data exploitation techniques to extract information and convert it into knowledge, which is the true value for the company, so that the rest of the management teams can turn it into action. It also carries out the diagnoses related to the operation of the company in relation to its strategic objectives, as well as detailing the nature of the market fluctuations, to identify and map the new market opportunities. Thus, the team of analysts will have the role of driver and catalyst of the information generated by the different management teams, and synthesizer of the information for the whole organization in terms of actionable intelligence.

In short, the new $21^{\text {st }}$ century company must be equipped with an organizational structure that not only allows to know the needs of the ends of the production-distribution chain, but also the needs of the different stages in the production chain, supported by algorithms capable of translating the data into information and knowledge for decentralized decision making and actionable intelligence.

\section{The Future of Business Intelligence}

$\mathrm{Bl}$ understood as the new business model has the task of bridging the gap between business process management and business strategy (Zeller, 2008). So it is necessary to explore how BI helps to learn how to deal with generalized and collective interactions, and the management of incremental technological tools (IPads and Mobiles) that change their characteristics in very short periods of time. This learning spreads to the management of the company's own activities, such as the interactive meetings of different management teams, the channeling of brainstorming and the role of moderator of the debates proposed by the teams. In other words, how good the model of Business Intelligence is to manage these new problems.

In the $\mathrm{BI}$ model, strategies allow end users not only to access information, but also to have the technological tools they need to understand the meaning of the information extracted and determine how to use it to achieve the desired result. These strategies require, whether in real time or not, combining and feedback of competencies, skills, and abilities, as decisions are increasingly decentralized. This involves exploring the impact of the decentralization of the access to information, to knowledge and to decision making, on the behavior of the people who make up the company, especially the executives.

In an organizational architecture that allows the permeability between the different management teams, the BI model based on the generalized feedback of all those involved in the business activity and the stimulating and proactive participation in the business project, enables the discovery of what users do, how they do it and where they do it. It would be interesting to know how the user feels when doing it, that is, translate his emotions into data (analysis of feelings). Exploring this trend in the framework of the $\mathrm{BI}$ model can tell us if it is really a valuable and complementary knowledge.

\section{Conclusions}

The economy of intangibles is a great opportunity for companies to successfully and rapidly change their business architecture, by applying intelligence in the comprehensive management of strategic intangibles: interaction, exploitation of large datasets, reputation, and communication and corporate social responsibility.

The "adaptation" strategies implemented by the companies, based on a traditional organizational scheme, present serious limitations to face the new challenges posed by the knowledge economy and the technological revolution: continuous turbulence of the environment in which it operates, new forms of decentralized management and organization, new technological tools, etc.

The ability to change and the flexibility of the company can hardly be developed if the technological approach of the business intelligence model persists. The different manifestations of intelligence have in common that they allow "to know before" (detection, discernment and dissemination) and "to know more" (integration, interpretation, analysis), and generate a competitive advantage based on knowledge and on the capacity of adequate response (prediction and prognosis). Hence, 
the survival of the company is linked to its ability to capture the intelligence and experience (talent) of people and, based on new technologies and management systems, transform them into useful knowledge that encourages intelligence in the process of learning, creativity and organizational innovation of the company.

The new architecture of the 21st century company will be formed by multi-purpose, transparent and interrelated teams, articulated by the team of analysts who will have the role of driver and catalyst of the information generated by the different management teams. They will foster horizontal management based on the responsibility and the commitment of the employees and not so much on their control.

\section{References}

[1] Ahumada Tello, E. \& Perusquia Velasco, J. (2016). Inteligencia de Negocios: Estrategia para el Desarrollo de la Competitividad en Empresas de Base Tecnológica en Tijuana, B.C.. Contaduría y Administración (61), pp. 127-158. (Available at www.sciencedirect.com).

[2] Allorza, Ángel (2016). Gestión Integrada e Integral de los Intangibles Estatégicos: Marca y Reputación. Cre.100do.es. Nuevas Grandes Empresas. $5380 \mathrm{eab} 2 \mathrm{c} 2 \mathrm{~b} 5$

https://www.cre100do.es/documents/11036/148195/intangibles/43e74a61-a138-42c5-9e24-

[3] Azevedo, A. \& Santos, M. (2009). Business Intelligence - State of the Art, Trends, and Open Issues. KIMIS2009 - International Conference on Knowledge Management and Information Sharing.

[4] Azma, F. \& Ali Mostafapour, M. (2012). Business Intelligence as a Key Strategy for Development Organizations. Procedia Technology (1), pp. 102-106. Available online at www.sciencedirect.com.

[5] Ballantyne, D. (2003). A Relationship-mediated Theory of Internal Marketing. European Journal of Marketing, Vol. 37 (9), pp.1242-1260, https://doi.org/10.1108/03090560310486979

[6] Beatham, S., Anumba Ch., Thorpe, T. \& Hedges, I. (2004). KPIs: A Critical Appraisal of their Use in Construction. Benchmarking: An International Journal, Vol. 11 (1), pp. 93-117, https://doi.org/10.1108/14635770410520320

[7] Blecker, T. \& Nizar, N. (2006). Mass Customization: State-of-the-Art and Challenges. Mass Customization: Challenges and Solutions. Chap. 1. (International Series in Operations Research \& Management Science). Book series ISOR Vol. 87.

[8] Bolumole, Yemisi A. (2001). The Supply Chain Role of Third-Party Logistics Providers. The International Journal of Logistics Management. Vol. 12, (2), pp. 87-102.

https://doi.org/10.1108/09574090110806316.

[9] Brand Finance - Global 500. (2017). The Annual Report on The World's Most Valuable Brands. (Brand Finance). February. London. http://brandfinance.com/images/upload/global_500 _2017_locked_website.pdf.

[10] Camisón Zornosa, C. (2016). El Modelo de Empresa Basado en Activos Intangibles: Hacia una Empresa Responsable, Sostenible y Competente. (Estudis Económics. Consellería d'Economia Sostenible, Sectors Poductius, Comerc i Treball). Generalitat Valenciana.

[11] Chee, Timothy, et. al. (2009). Business Intelligence Systems: State of the Art Review and Contemporary Applications. Symposium on Progress in Information \& Communication Technology.

[12] Christensen, Clayton M. (2016). The Innovator's Dilemma: When New Technologies Cause Great Firms to Fail. (The Management of Innovation and Change Series. Harvard Business Review Press).

[13] Davenport, Thomas, et. al. (2010) Competing on Talent Analytics. Harvard Business Review. October .

[14] Filofteia Tutunea, M. (2017). Business Intelligence Solutions for Mobile Devices - an Overview. Procedia Economics and Finance, (27), pp. 160-169. ScienceDirect-Elsevier. 
[15] Fordham, David R., et. al. (2017). Business Intelligence: How Accountants Bring Value to The Marketing Function. Strategic Finance, May, p. 25.

[16] Ghanzanfari, M., Jafari, M. \& Rouhani, S. (2011). A Tool to Evaluate the Business Intelligence of Enterprise Systems. Journal: Scientia Iranica E. Vol. 18, (6), pp. 1579-1590.

[17] Highfield, T. et. al. (2014). A 'Big Data' Approach to Mapping the Australian Twittersphere. Advancing digital humanities: Research, methods, theories. (Eds. Paul Arthur \& Katherine Bode). Palgrave Macmillan, pp. 113129.

[18] ICTC. (2016). Big Data \& The Intelligence Economy. (Report: Information and Communications Technology Council). Canada.

[19] Isik, O., Jones, C. \& Sidorova, A. (2013). Business Intelligence (BI) Success and the Role of BI Capabilities and Decision Environments. Information \& Management, Vol. 50 (1), January, pp. 13-23. Elsevier.

[20] Khan, A. \& Quadri, S.M.K. (2012). Business Intelligence: An Integrated Approach. Business Intelligence Journal. Vol. 5 (1). January.

[21] Klimoski, R, et. al. (2016). Use of Workforce Analytics for Competitive Advantage. (SHRM Foundation). May. (http://www.shrmfoundation.org).

[22] Knemeyer, A.M., et. al. (2003). Logistics Outsourcing Relationships: Customer Perspectives. Journal of Business Logistics, Vol. 24 (1), pp. 77-109. Spring.

[23] Olszak, C \& Ziemba, E. (2007). Approach to Building and Implementing Business Intelligence Systems. Interdisciplinary Journal of Information, Knowledge, and Management (2), pp. 135-148

[24] Phan, D. D. \& Vogel, D. R. (2010). A Model of Customer Relationship Management and Business Intelligence Systems for Catalogue and Online Retailers. Information \& Management (47), pp. 69-77.

[25] Ranjan, Jayanthi (2009). Business Intelligence: Concepts, Components, Techniques and Benefits. Journal of Theoretical and Applied Information Technology. Vol. 9 (1), pp. 60-70.

[26] Rusaneanu A. (2013). Comparative Analysis of the Main Business Intelligence Solutions. Informatica Economica (17), pp. 148-156.

[27] Saran, C. (2012). Almost a third of BI projects fail to deliver on business objectives. (Available at : http://www.computerweekly.com/news/2240113585/Almost-a-third-of-BI-projects-fail-to-deliver-on-businessobjectives).

[28] Satiko Ishikiriyama, C., Miro, D. \& Simões Gomes, C. (2015). Mining Business Intelligence: A Small Sample of What Words Can Say. Procedia Computer Science (55), pp. 261 - 267. ScienceDirect-Elsevier.

[29] Smith, H. \& Fingar, P. (2003). Business Process Management: The Third wave. (Editor: Meghan-Kiffer). WFMC - BPMl.org. USA.

[30] Stavrianou A., Andritsos P, \& Nicoloyannis N. (2007). Overview and Semantic Issues of Text Mining. SIGMOD Record, (36), pp. 23-34.

[31] Thamir, A. \& Poulis, E. (2015). Business Intelligence Capabilities and Implementation Strategies. International Journal of Global Business. Vol. 8 (1), pp. 34-45, June.

[32] Thompson, WJJ, \& Van der Walt JS. (2010). Business intelligence in the cloud. Journal of Information Management, Vol. 12 (5).

[33] Venkatesh, Uma D. \& Namana, S. (2016). Business Intelligence for IBM with Smarter Self-Service Analytics. (Editor IBM) http://hh.diva-portal.org/smash/get/diva2:1080951/FULL TEXT 01.pdf. 
[34] Von Bergen, P., Hinkelmann, K. \& Friedrich Witschel, H. (2015). Adapting an Enterprise Architecture for Business Inteligence. (Editors: S. España J. Ralyté, P. Soffer, J. Zdravkovic and O. Pastor (Eds)). PoEM, pp. 41-50.

[35] Vouri, Vilma (2006). Methods of Defining Business Information Needs. Frontier of E-Business Research.

[36] Wilding, R. \& Juriado, R. (2004). Customer Perceptions on Logistics Outsourcing in the European Consumer Goods Industry. International Journal of Physical Distribution \& Logistics Management, Vol. 34 (8), pp. 628644, $\quad$ https://doi.org/10.1108/09600030410557767.

[37] Yeoh, W. \& Koronios, A. (2010). Critical Success Factors for Business Intelligence Systems. Journal of Computer Information Systems, Vol. 50 (3), pp. 23-32. Spring.

[38] Yu, Ying, W., Xin , Z, Ray, Y. \& Huanga, G. (2016). E-commerce Logistics in Supply Chain Management: Practice Perspective. ScienceDirect. Procedia CIRP (52), pp. 179-185. 